\title{
Purification and Characterization of a Novel CGTase from Alkaliphilic Bacillus flexus Isolated from Lonar lake, India
}

\author{
A. Shinde Vinod* and S.M. More \\ Department of Microbiology, Yeshwant Mahavidyalaya, Nanded- 431602 (M. S.), India \\ *Corresponding author
}

\section{A B S T R A C T}

Keywords

Cyclodextrin glycosyltransferase (CGTase); purification; Phenyl sepharose.

\section{Article Info}

Accepted:

12 June 2016

Available Online:

10 July 2016
Production and purification of Cyclodextrin glycosyltransferase (CGTase) from Alkaliphilic Bacillus flexus isolated from Lonar lake, India was investigated in present study. Production was carried out using medium containing starch, yeast extract, peptone $\mathrm{MgSO}_{4} \cdot 7 \mathrm{H}_{2} \mathrm{O}$. The crude enzyme was collected by centrifugation and partially purified using ammonium sulphate precipitation method. This partially purified enzyme was further purified using phenyl sepharose column chromatography .The enzyme obtained had molecular weight of $77.58 \mathrm{kDa}$ which is confirmed by SDS PAGE and Mass spectroscopy.

\section{Introduction}

Alkaliphilic microorganisms have attracted much interest in the past few decades because of their ability to produce extracellular enzymes that are active and stable at high $\mathrm{pH}$ values (Atanasova et al., 2009; Antranikian et al., 2005). The main natural habitats of alkaliphiles are alkaline environments. Naturally occurring alkaline environments, such as carbonate springs, alkaline soils, and soda lakes, are characterized by their high basic $\mathrm{pH}$ values ( $\mathrm{pH} 8.0-11.0)$ due to the presence of high concentrations of sodium carbonate salts formed by evaporative concentration (Horikoshi, 1999; Van den Burg, 2003).
Soda lakes are widely distributed all over the world; however, as a result of their inaccessibility, few have been explored from a microbiological point of view (Grant et al., 2000).

Cyclodextrin glycosyl transferase (CGTase, EC 2.4.1.19) is an important industrial enzyme, unique in its ability to convert starch and related glycans into non-reducing, cyclic malto-oligosacchrarides called cyclodextrins (CDs) via a cyclization reaction, an intramolecular transglycosylation reaction (Biwer et al., 2002). Moreover, it is an important hydrolytic 
enzyme that carries out reversible intermolecular coupling and disproportionation of maltooligosaccharides (Biwer, 2002; Savergave et al., 2008). CDs are non-reducing cyclic structures consisting mainly of 6,7 or 8 glucose residues, joined by $\alpha-(1,4)$ linkages, for $\alpha-\beta-$ and $\gamma \mathrm{CD}$ cyclodextrin, respectively. Among the three types of cyclodextrins, $\beta-C D$ is of high interest due to the size of its non-polar cavity which is suitable to encapsulate several guest molecules; its low solubility in water which facilitates its separation from the reaction mixture. Moreover, $\beta-C D$ inclusion complexes are easily prepared and more stable (Otero-Espinar et al., 2010; Astray et al., 2009). CGtase is produced by species of Bacillus, Brevibacterium, Clostridium, Klebsiella, Micrococcus. The production of CGTase became attractive only when alkalophilic Bacillus species were introduced as production organism (Biwer et al., 2002; Gawande et al 1999). Various unit operations used in downstream processing for getting pure protein constitute a large part of production cost. Many reports suggest purification strategies of using adsorption of CGTase on starch, which have a drawback that CGTase reacts with starch and a additional step to remove Cyclodextrin is required (Leaver et al., 1987). In the present work attempts were made to purify CGTase produced by alkalophilic Bacillus flexus, using phenyl sepharose column chromatography. And purity of the enzyme was then confirmed by SDS PAGE and Mass spectroscopy by confirming the molecular weight.

\section{Materials and Methods}

Strain: The strain used for production and purification of CGTase is the isolate isolated from Lonar lake and termed as BI 56A, which is identified by $16 \mathrm{~S}$ rRNA sequencing and according to phylogenic analysis designated as Bacillus flexus and the $16 \mathrm{~S}$
rRNA sequence was submitted to NCBI GenBank with Accession No. JX419382 (Heydrickx et al., 2004).

\section{Production of CGTase using Bacillus flexus}

The production medium used constitute of Solution 1: Starch $1.0 \%$ (w/v), peptone 0.5 $\%(\mathrm{w} / \mathrm{v})$, yeast extract $0.5 \%(\mathrm{w} / \mathrm{v}), \mathrm{K} 2 \mathrm{HPO} 4$ $0.1 \%(\mathrm{w} / \mathrm{v}), \mathrm{MgSO} 4.7 \mathrm{H} 2 \mathrm{O} 0.02 \%(\mathrm{w} / \mathrm{v})$ and Solution 2: Sodium bicarbonate 1\% (w/v) (Horikoshi et al., 1984).

The organism i.e. Bacillus flexus was inoculated in $510 \mathrm{ml}$ of inoclum medium which is same as that of production medium and enriched. After enrichment $10 \%$ of the inoculums was transferred to $100 \mathrm{ml}$ of production medium and incubated at $37^{\circ} \mathrm{C}$ in rotator shaker incubator for $24 \mathrm{hrs}$. at the end of incubation period, fermentation medium was centrifuged at $8000 \mathrm{rpm}$ for 10 minutes at $4^{\circ} \mathrm{C}$. The supernatant collected was assayed for CGTase activity and was used as crude enzyme for further study (Horikoshi et al., 1984).

\section{Cyclization activity of CGTase enzyme}

Cyclization activity of CGTase enzyme sample from isolates Bacillus flexus was determined by the phenolphthalein method (Goel and Nene, 1995). To $1.25 \mathrm{ml}$ of $4.0 \%$ soluble starch, $0.25 \mathrm{ml}$ purified CGTase was added. The reaction mixture was incubated for $30 \mathrm{~min}$ at $60^{\circ} \mathrm{C}$. The reaction was stopped by boiling for $5 \mathrm{~min}$ and $1.0 \mathrm{ml}$ of the reaction mixture was incubated with 4.0 $\mathrm{ml}$ of phenolphthalein solution. The decrease in phenolphthalein absorption at $550 \mathrm{~nm}$ reflected the amount of CD in the reaction which was quantitated from calibration curve. One unit of activity was defined as the amount of enzyme able to produce 1 mole of $\beta$-CD per minute under the appropriate condition. Monitoring 
CGTase activity on agar plate was performed by pouring mixture of methyl orange and phenolphthalein on Horikoshi medium (Park et al., 1989) or LB plate in the presence of $1 \%$ soluble starch.

\section{Purification of Enzyme}

The crude enzyme was used for further purification by ammonium sulphate saturation method, followed by Phenyl sepharose column chromatography.

The crude enzyme was subjected to ammonium sulphate extraction, in this procedure saturated ammonium sulphate solution of different concentration of $30 \%$, $50 \%$, and $70 \%$ was prepared. These solutions were mixed with mixture obtained earlier. The protein present in the crude enzyme were allowed to precipitate by keeping the mixture in cold conditions. The precipitate were then centrifuged at 5000 rpm for $20 \mathrm{~min}$, the pellets were collected by dissolving in phosphate buffer of $\mathrm{pH} 7.0$ and was used for further studies (Jogdand et al., 2008).

\section{Phenyl Sepharose Chromatography}

The partially purified enzyme mixture obtained after ammonium sulphate extraction was used for Binding study. Binding study was carried out at different ammonium sulphate concentration from $0.8 \mathrm{M}$ to $1.2 \mathrm{M}$. A chromatography column (15X $100 \mathrm{~mm}$ size ) was packed with phenyl sepharose and equilibrated with $25 \mathrm{mM}, \mathrm{pH}$ 7.0 Tris- $\mathrm{HCl}$ buffer containing $0.8 \mathrm{M}$ to $1.2 \mathrm{M}\left(\mathrm{NH}_{4}\right) \mathrm{SO}_{4}$, respectively. One $\mathrm{ml}$ of concentrated partially purified enzyme mixture was supplemented with $1 \mathrm{M}$ $\left(\mathrm{NH}_{4}\right) \mathrm{SO}_{4}$ and loaded to the equilibrated phenyl sepharose column. The elution was carried out by stepwise decrease in the ionic strength of $\left(\mathrm{NH}_{4}\right) \mathrm{SO}_{4}$ ranging from $0.25 \mathrm{M}$ to $0 \mathrm{M}$. fractions were collected and analysed for CGtase activity and protein concentration (Jogdand et al., 2008).

\section{SDS Page}

After the partial purification and farction collection, the fraction which shows more CGtase activity and protein concentration was selected and the homogeneity of enzyme in the eluted fraction was checked by SDS- PAGE on a vertical slab gel electrophoresis suing $7.5 \%$ acrylamide gel at constatnt current of $30 \mathrm{~mA}$ for $2 \mathrm{~h}$. Gel $(8 \mathrm{cmX} 12 \mathrm{~cm})$ was run according to the method of laemmli (Laemmli, 1970). The SDS-PAGE was performed, in order to check the homogeneity of the enzyme and to determine the molecular weight of the enzyme under denaturing conditions.

\section{Mass Spectroscopy Analysis}

The molecular weight and purity was confirmed by mass spectroscopy analysis. The fractions were sent to Department of proteomics, National Chemical Laboratory (NCL), Pune for mass spectroscopy analysis and the samples were analysed (Nomoto et al 1986).

\section{Result and Discussion}

The purpose of this work is the development of simple and effective CGTase purification process immediately from cultural broth. Microorganisms for screening were grown on identical composition medium. The strain producer of CGTase was selected according the highest cyclization provided activity (for $1 \mathrm{ml}$ of cultural broth). Most of the bacterial strains are known to produce other amylolitic enzymes besides CGTases (Volkova et al., 2000). Thus the measurement of cyclyzing and dextrinizing activity was conducted during purification process. 
Fig.1 SDS PAGE Analysis Report of CGTase from Bacillus flexus (56A JT) with Standard Markers

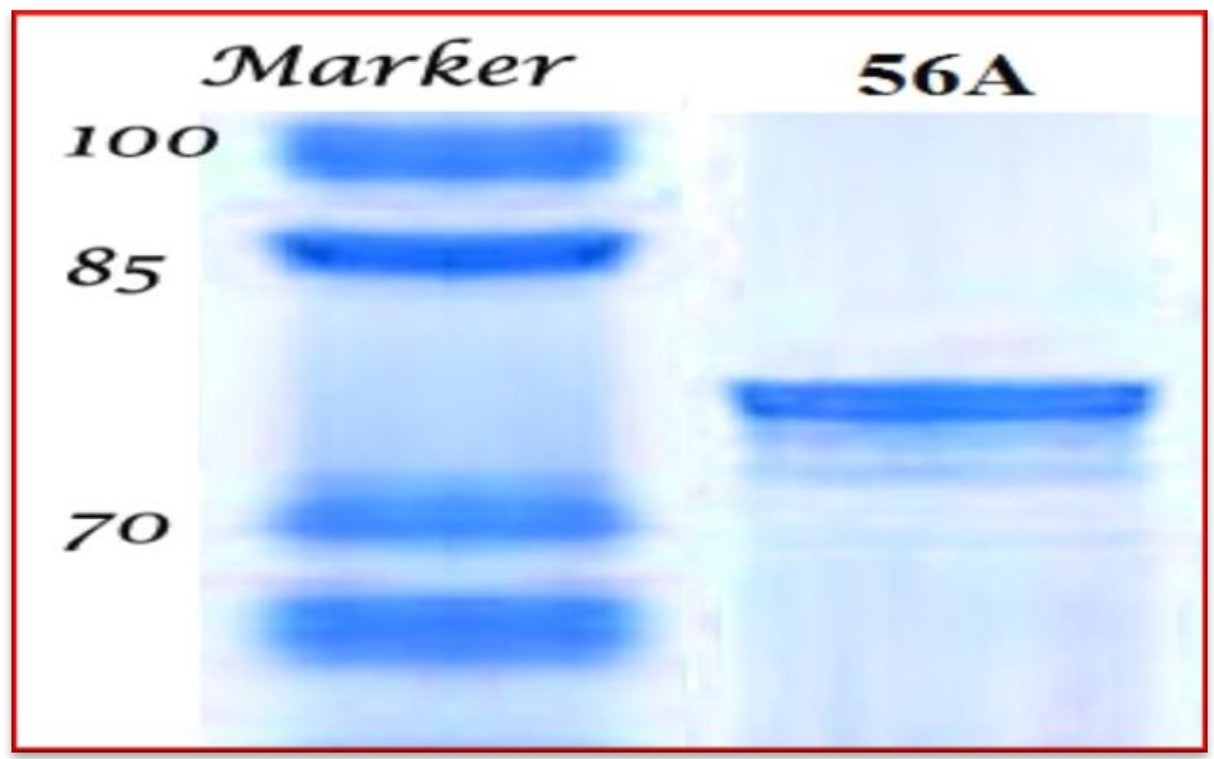

Fig.2 Mass Spectroscopy analysis of partially purified CGTase produced by Bacillus flexus

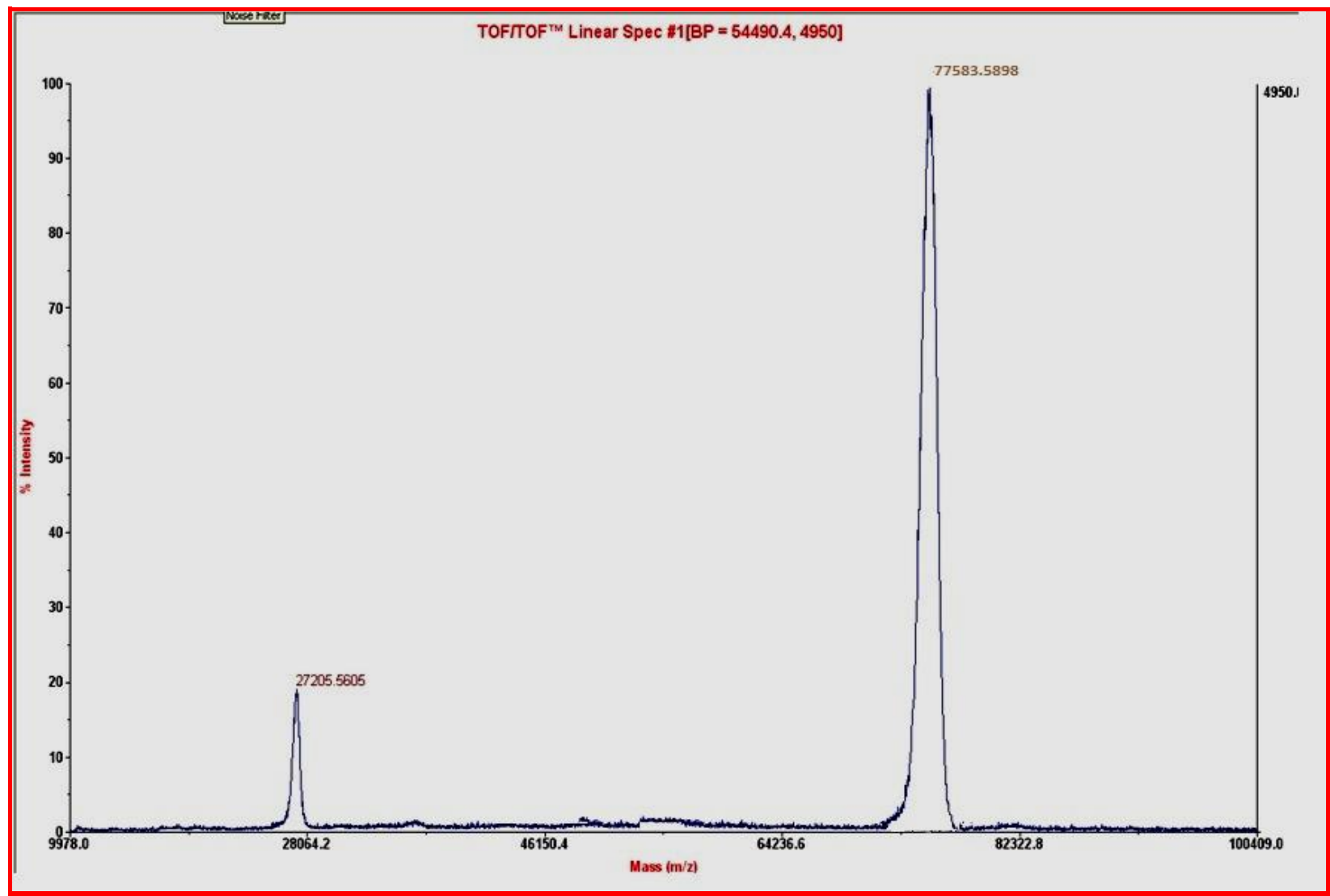




\section{Purification of the CGTase}

Usually the gel-filtration is used for $\mathrm{CD}$ removal from affinity complex with CGTase (Larsen et al., 1998; Bovetto et al., 1992). But the pretreatment of applying matter, for instance, concentration and careful calculation, makes this step hard. CGTase from Alkaliphilic Bacillus flexus was purified by ammonium sulphate saturation method followed by phenyl sepharose column chromatography, CGTase was found to be eluted using $0.085 \mathrm{M}$ ammonium sulphate from phenyl sepharose column.

Different separation procedures have been previously applied for obtaining purified CGTases, and in most cases, three or four purification steps were applied including ultrafiltration, gel filtration, starch adsorption and ion exchange chromatography or ammonium sulfate precipitation and two steps ion exchange chromatography (Abdelnasser et al., 2012). Yim et al purified the CGTase using DEAE sephadex A-50 followed by DEAE Sepharose CL-6B (Yim et al., 1997).

\section{Estimation of Molecular weight of the Enzyme}

Some of the physical and chemical properties was identified for purified CGTase. The purified enzyme obtained from phenyl sepharose column showed a single band by SDS PAGE, which confirms that the homogeneity of the enzyme (Fig 1). Molecular weight of CGTAse was estimated as $77.58 \mathrm{kDa}$, which is confirmed by Mass spectroscopy (Fig 2). Most of the reported CGTases are monomeric in nature with molecular weight between 60 and $110 \mathrm{kDa}$. However, CGTases with lower molecular weight have been also reported, such as 33 $\mathrm{kDa}$ from Bacillus coagulans and as $56 \mathrm{kDa}$ from Bacillus sphaericus strain 41 (Abdelnasser et al., 2012).
In conclusion, in this study, we report purification and characterization of CGTase from Alkaliphilic Bacillus flexus isolated from Lonar lake, India. Enzyme purification to homogeneity was achieved by phenyl sepharose column chromatography. Starch adsorbtion chromatography is one of the popular methods for the initial capture of the CGTase, but it demands gel filteration for the separation of $\mathrm{CD}$ formed during the elution of enzyme from the column. Though the rate of purification is slow but we have purified the enzyme successfully without formation of $\mathrm{CD}$ in the column. CGTase reported in the study is having molecular weight of $77.58 \mathrm{kDa}$ which is confirmed by SDS PAGE and Mass spectroscopy. Thus we suggest CGTase purified with the proposed chromatographic scheme is of benefit in comparison to crude enzyme in starch hydrolysis process.

\section{References}

Abdelnasser, S.S., Ibrahim, Ali, A., AlSalamah, Mohamed, A., El-Tayeb, Yahya, B., El-Badawi, Garabed Antranikian. 2012. A Novel Cyclodextrin Glycosyltransferase from Alkaliphilic AmphiBacillussp. NPST10: Purification and Properties. Int. J. Mol. Sci., 13: 10505-10522.

Antranikian, G., Vorgias, C.E., Bertoldo, C. 2005. Extreme environments as a resource for microorganisms and novel biocatalysts. Adv. Biochem. Eng. Biotechnol., 96: 219-262.

Astray, G., Gonzalez-Barreiro, C., Mejuto, J., Rial-Otero, R., Simal-Gandara, J. 2009. A review on the use of cyclodextrins in foods. Food Hydrocoll., 23: 1631-1641.

Atanasova, N., Kitayska, T., Yankova, D., Safarikova, M., Tonkova, A. 2009. Cyclodextrin glucanotransferase production by cell biocatalysts of 
alkaliphilic bacilli. Biochem. Eng. J., 46: 278-285.

Biwer, A., Antranikian, G. and Heinzle, E. 2002. Enzymatic production of cyclodextrins. Appl. Microbiol. Biotechnol., 59: 609-617.

Bovetto, L.J., Backer, D.P., Villette, J.R., Sicard, P.J., Bouquelet, S.J. 1992. "Cyclomaltodextrin Glucanotransferase from Bacillus circulansE 192." Biotechnol. Appl. Biochem., 15: 48 58.

Leaver, G., J.R. Conder, J.A. Howell. 1987. A method development study of the production of albumin from animal blood by ion exchange chromatography. Separ. Sci. Technol., 22: 2037-2059.

Gawande, B.N., Goel, A., Patkar, A.Y., Nene, S.N. 1999. Purification and Properties of a Novel Raw StarchDegrading Cyclomaltodextrin Glucanotransferase from Bacillus firmus. Appl. Microbiol. Biotechnol., 51: 504-509.

Goel, A., Nene, N.S. 1995. Modifications in the phenolphthalein method for spectrophotometric estimation of beta cyclodextrin. Starch/starke 47: 399400.

Grant, W.D., Jones, B.E. 2000. Alkaline Environments. In Encyclopaedia of Microbiology, $2^{\text {nd }}$ ed.; Lederberg, J., Ed.; Academic Press: New York, NY, USA, pp. 126-133.

Heyndrickx, M., N.A. Logan, L. Lebbe, M. Rodriguez-Diaz, G. Forsyth, J. Goris,P. Scheldeman and De Vos, P. (2004). Bacillus galactosidilyticus sp. nov., an alkali-tolerant, -galactosidase producer. Int. J. Syst. Evol. Microbiol., 54: 617621.

Horikoshi, K., Kato, K. 1984. Immobilized cyclodextrin glucanotransferase of an alkalophilic Bacillus species No. 38-2. Biotechnol. Bioeng., 26: 595-598.
Horikoshi, K. 1999. Alkaliphiles: Some applications of their products for biotechnology. Microbiol. Mol. Biol. Rev., 63: 735-750.

Jogdand, V.V., Savergave, L.S., Dhule, S.S., Nene, S.N., Gadre, R.V. 2008. Production and single step purification of cyclodextrin glycosyltransferase fromn alkalophilic Bacillus firmus by ion exchange chromatography. Biochem. Engineering J., 39: pp- 510515.

Laemmli, U.K. 1970. Cleavage of structural proteins during the assembly of the head of bacteriophage T4. Nature, 227: 680-685.

Larsen, K.L., Duedahl-Olesen, L., Christensen, H.J.S., Mathiesen, F., Pedersen, L.H., Zimmermann, W. 1998. Purification and Characterization of Cyclodextrin Glycosyltransferase from PaeniBacillussp. F8. Carbohydrate Res., 310: 211-219.

Nomoto, M., Chen, C.C., Sheu, D.C. 1986. Purification and Characterization of Cyclodextrin Glucanotransferase from an Alkalophilic Bacterium of Taiwan. J. Agri. Biol. Chem., 50(11): 2701 2707.

Otero-Espinar, F.J., Luzardo-Alvarez, A., Blanco-Mendez, $\quad$ J. 2010. Cyclodextrins: More than Pharmaceutical Excipients. Mini-Rev. Med. Chem., 10: 715-725.

Park, C.S., Park, K.H., Kim, S.H. 1989. A rapid screening method for alkaline $\beta$ cyclodextrin glucanotransferase using phenolphthalein-methylorangecontaining solid medium. Agric. Biol. Chem., 53: 1167-1169.

Savergave, L.S., Dhule, S.S., Jogdand, V.V., Nene, S.N., Gadre, R.V. 2008. Production and single step purification of cyclodextrin glycosyltransferase from alkalophilic Bacillus firmusby ion 
exchange chromatography. Biochem. Eng. J., 39: 510-515.

Van den Burg, B. 2003. Extremophiles as a source for novel enzymes. Curr. Opin. Microbiol., 6: 213-218.

Volkova, D.A., S.A. Lopatin, V.P. Varlamov. 2000. One step affinity purification of Cyclodextrin Glucanotransferase from Bacillus sp. 1070. Biocatalysis-2000: Fundamental
\& Applications, Vol. 41, No. 6, Supplement pp 67-69, Vestnik Moskovskogo Universiteta. Khimiya.

Yim, D.G., H.H. Sato, Y.H. Park, Y.K. Park. 1997. Production of cyclodextrin from starch by cyclodextrin glycosyltransferase from Bacillus firmusand characterization of purified enzyme. J. Ind. Microbiol. Biotechnol., 18: 402-405.

\section{How to cite this article:}

Shinde Vinod, A., and More, S.M. 2016. Purification and Characterization of a Novel CGTase from Alkaliphilic Bacillus flexus Isolated from Lonar lake, India. Int.J.Curr.Microbiol.App.Sci. 5(7): 164-170. doi: http://dx.doi.org/10.20546/ijcmas.2016.507.016 